\title{
Sol-gel approaches in the synthesis of membrane materials for nanofiltration and pervaporation
}

\author{
B.C. Bonekamp \\ R. Kreiter \\ J.F. Vente \\ Book chapter published in Sol-gel methods for materials processing (NATO Science for Peace \\ and Security Series C: Environmental Security) (2008), DOI 10.1007/978-1-4020-8514-7, \\ pp 47-65
}




\author{
BEN C. BONEKAMP, ROBERT KREITER, JAAP F. VENTE* \\ Energy research Centre of the Netherlands, P.O. Box 1, 1755 ZG Petten, The \\ Netherlands.
}

\begin{abstract}
Molecular separation using membranes is widely considered as an energy-efficient alternative for conventional industrial separation techniques. For the preparation of such membranes sol-gel technology is highly suitable. Using sol-gel techniques thin $(50-100 \mathrm{~nm})$ amorphous nanoporous layers having pore sizes in the micropore $(<2 \mathrm{~nm})$ or fine mesoporous $(<5$ $\mathrm{nm}$ ) region can be prepared on a porous substrate. These layered porous systems, usually in tubular form, can be used for nanofiltration, pervaporation and gas separation applications. The application window is dependent on the material properties, such as the pore size and pore size distribution, the interfacial properties of the pores, and the defect density. The success of this technology in actual industrial applications strongly depends on reproducible large scale production of the sol-gel membranes and on a sufficient stability of the membranes with respect to flux and selectivity. In addition the production cost of the full membrane system is an important aspect. Here, we will focus on the more chemical aspects in the membrane preparation. Main topics are synthesis and properties of the sols, the preparation of microporous thin films, and the search for membrane materials that have a high hydrothermal stability.
\end{abstract}




\section{Introduction}

Molecular separation processes have great influence on the total use of energy in industry, chemical production costs and the price of products for the consumer. As an example, about $40 \%$ of final energy use in the Dutch (petro)chemical industry, an estimated $190 \mathrm{PJ} / \mathrm{year}$, is applied to separation processes alone. The most commonly used technology is distillation, which has a very low intrinsic exergetic efficiency of $10 \%$. Membrane technology has been widely recognized as one of the most promising energy-efficient alternatives. Demands of flux, selectivity and lifetime, set on the membranes performances lead to the use of thin microporous layers. In practice this means layers as thin as $50-100 \mathrm{~nm}$, a pore diameter of less than $2 \mathrm{~nm}$ and a very high porosity. ${ }^{1,2}$ These layers are too thin to be self supporting and a dedicated support has to be used (supported thin films shown in Figure 1). As the selectivity depends on the pore characteristics and defect density, strict control over the parameters of support manufacturing and sol synthesis and coating is essential for obtaining high quality membranes. ${ }^{3}$ Proper characterization techniques, such as dynamic light scattering and permporometry, are important for effective membrane development and production.

Figure 1. SEM pictures of a. fracture surface of a microporous silica sol-gel film on a mesoporous $\gamma$-alumina substrate; $b$. mesoporous titania sol-gel film on a macroporous $\alpha$-alumina substrate; c. surface of a microporous methylated silica thin film; d. methylated silica thin film $(\sim 50 \mathrm{~nm})$

One of our main goals is the development of methods for the reproducible preparation of microporous membrane layers (see Figure 1) on tubular mesoporous substrates of up to 1 meter long. We have selected sol-gel technology as a prime tool for achieving this. The sol-gel membranes were successfully used for gas separation experiments, e.g. hydrogen/ methane and hydrogen/ carbon dioxide separation. ${ }^{4}$ These thin films are an alternative for crystalline zeolite membranes despite the broader intrinsic pore size distribution. ${ }^{5}$ We also discovered that such microporous films are very suitable for dewatering of organic liquids by pervaporation. ${ }^{6}$

As sol-gel membranes have a very thin and often amorphous structure in combination with a very high specific surface area, there is a significant driving force towards states having a lower energy. In practice, this means that the sol-gel film has a tendency to reorganize to a lower surface area or even crystallize. Active operation of sol-gel membranes seems to accelerate this transformation. Therefore, the challenge is to reduce the kinetics of this process to obtain membranes with sufficient lifetime for industrial applications. Especially the hydrothermal stability is an issue. In a dry atmosphere, these inorganic membranes can function up to temperatures of $300{ }^{\circ} \mathrm{C}$. In the presence of small amounts of water the stability decreases very rapidly.

Nanofiltration membranes demand pore size control in the region of 1-3 nm to achieve molecular mass cut-off values in the region of 1000-5000 Dalton. The materials should have a very low acid solubility for a number of important commercial applications.

In this paper, we present a brief overview of sol-gel technology for the preparation of porous membrane layers suitable for molecular separations. The preparation of the mesoporous support layers made from alumina or titania is also included. Furthermore, a historical path of the development of microporous selective layers is followed, starting from pure silica $\left(\mathrm{SiO}_{2}\right)$, via organic end groups towards bridging organic groups in the silica structure. As alternatives metal oxide membranes based on titania and zirconia are discussed. The focus is on sol preparation and the resulting properties of thin film coatings that are suitable for large scale production of membrane tubes.

\section{Sols and Thin-Films}

The transition of sol species into a gel state is an important step in the formation of a porous structure. This transition is followed by a consolidation step consisting of drying and calcining at an appropriate temperature. For the sake of the current discussion, we consider a sol-gel process as 
a route to inorganic or inorganic-organic hybrid materials via intermediate individual sol and gel states.

\subsection{SOL PREPARATION}

Microporous thin films for molecular separation purposes can be obtained from various sol types. The type of sol needed depends on the mechanism of pore formation during the deposition of the thin films. ${ }^{7}$ Microporous films can be prepared with and without the deliberate addition of pore templates. In the former case it is difficult to obtain pores below $2 \mathrm{~nm}$. In general, this method is more suitable for obtaining porosity in the small mesoporous region. In contrast, for the formation of crystalline microporous structures such as zeolites pore directing agents are commonly used, even for the smallest pore sizes. ${ }^{8}$

The preparation of sols for membrane preparation is in general a two step process. Starting from alkoxide precursors, oxides are obtained via hydrolysis and condensation steps. For siliconbased precursors it is generally accepted that these two processes occur consecutively, whereas for metal alkoxides these two processes cannot be distinguished, due to the faster kinetics. Hydrolysis and condensation can be represented by the following equations:

$$
\mathrm{M}(\mathrm{OR})_{\mathrm{z}}+\mathrm{H}_{2} \mathrm{O}->\mathrm{M}(\mathrm{OH})(\mathrm{OR})_{\mathrm{z}-1}+\mathrm{ROH}
$$

$$
\text { -M-OH+M-OR->-M-O-M- + ROH }
$$

The sol species formed can either consist of fractal-like or polymeric particles or of dense and possibly crystalline structures. The nature of these building blocks can be tailored by appropriate selection of the reaction conditions. For example, in the case of silicon alkoxides, the use of a base catalyst leads to dense particles whereas an acid catalyst leads to open polymeric species. ${ }^{9}$ During the gelation stage, controlled particle packing without agglomeration is important, especially for dense particles. For polymeric sol particles interpenetration plays a crucial role. For both cases the sol-gel transition occurring during the drying of supported thin films is different from that occurring in bulk sols. The formation of microporous silica thin films requires sols that consist of relatively linear species with limited branching. The interpenetration of such species can be given by:

$$
M_{1,2} \propto r_{c}^{D 1+D 2-3},,^{10}
$$

where $\mathrm{M}_{1,2}$ is the number of intersections, $r_{c}$ the species radius and D1 and D2 are the fractal dimension of the respective species. So when the fractal dimension of the sol species is $<1.5$ interpenetration is almost not restricted and small pores can form during the drying process.

In contrast, condensation of titanium and zirconium alkoxides gives rise to dense particles originating from a nucleation and growth mechanism. Apart from the differences in sol particles, the reaction kinetics are much faster compared to those of silica-based sols. ${ }^{11}$ One of the main issues in preparing these sols is to slow down the kinetics and to limit the particle growth to 5 $10 \mathrm{~nm}$. In addition, metal oxides have a tendency to crystallize during heat treatment or during membrane application. ${ }^{12}$

For the characterization of sol species in a liquid medium Small Angle X-ray Scattering (SAXS) and Dynamic Light Scattering (DLS) can be used. SAXS can be applied to determine particle size and fractal dimensions of sol species. Unfortunately, SAXS equipment (often at a synchrotron facility) is not routinely accessible. DLS is a much more convenient alternative for a sol-gel laboratory as a first tool for the determination of the particle size distribution. ${ }^{13}$ 


\subsection{FORMATION OF A THIN FILM AND THE SOL-GEL TRANSITION}

Dip-coating (Figure 2) is a suitable and well-known method for preparing thin film coatings from sols. This method can be used for coating of sols on macroporous and mesoporous substrate tubes. The physical processes that occur during film formation were extensively studied by Brinker et al. ${ }^{14}$ During evaporation of the solvent the water concentration strongly increases and influences the ongoing reactions. At the same time, gelation starts to occur. When menisci are formed in the network (the second drying stage) the network collapses due to capillary forces until the network strength prevents further collapse. At this stage the pore structure is formed. Polymeric sol networks are consolidated by further condensation reactions. Solvent molecules may function as a pore template. The pore size can also be controlled by adding pore directing agents on purpose. ${ }^{15,16}$

Figure 2. Dip-coating of membrane tubes

As stated earlier, control over the defect density is of eminent importance to reach molecular separation with an acceptable selectivity. However, repairing defects in calcined thin films by application of second sol-gel coating often leads to unsatisfactory results. This can be ascribed to dewetting phenomena reminiscent to those occurring in thin polymer films. ${ }^{17}$ Occasionaly, this is also observed in single-layer coatings of sol-gel films (Figure 1d). The relation between the dewetting phenomenon and specific interactions of substrate and the coating liquid is not fully understood. This effect decreases the membrane yield in production and may also affect the adherence of the thin film after calcining. Therefore, applying a single sol-gel layer of sufficient thickness is to be preferred over multi-coating approaches. To achieve this, suitable sols and substrates having a low defect density are crucial.

\section{Structure of Porous Supports}

\subsection{DEFECTS}

For defect free films the intrinsic micropore characteristics, such as pore size distribution, tortuosity, and connectivity are the determining factors for the separation performance. In addition, the performance is influenced by the physico-chemical properties of the pore interfaces, such as wettability, presence of adsorption sites etc. The selectivity decreases when channels are present that are much larger than the intrinsic pore size. These so-called defect pores can be formed during the dip-coating process, due to asperities, larger voids, and dust particles (Figure 3). Alternatively, shrinkage and interaction with the substrate during the drying/consolidating stage can lead to microcrack formation. Defects in the top-layer can also originate from the larger pores present in the support. The use of clean rooms during the coating procedure reduces the influence of dust particles and enhances the quality of the film. ${ }^{18}$ Other important steps are the pre-treatment of the substrates and sol filtration prior to coating. The support structure must be smooth, flawless and homogeneous to obtain defect free sol-gel membranes. This can only be achieved through the application of a multilayer support system. ${ }^{19}$

Figure 3. Optical micrographs of the surface of a microporous zirconia thin film having a high defect density (left) and a defect poor microporous methylated silica thin film (right)

\subsection{MESOPOROUS SOL-GEL LAYERS: $\gamma$ - ALUMINA AND TITANIA}

Mesoporous $\gamma$-alumina obtained from boehmite sols $\left(\gamma-\mathrm{AlO}(\mathrm{OH})\right.$, Yoldas $\left.{ }^{20}\right)$ were developed by Leenaars. ${ }^{21}$ The pore size is determined by the plate-like structure of the primary particles in the boehmite sols consisting of ellipsoidal aggregates of these platelets. The aggregates are restructuring during drying and calcining of a coating. However, remnants of the aggregates after 
the sol-gel transition in a coating may cause larger intra-aggregate pores. Such larger pores (i.e $>20$ $\mathrm{nm}$ ) can be observed by bubble number porometry but are hard to observe with a Scanning Electron Microscope. The plate-like structure facilitates stress relaxation during drying stages. If required, further stress relaxation can be obtaining by adding suitable polymers to the coating sol. Stress relaxation is much more difficult in sol-gel coatings from sols with spherical particles, such as titania sols. Here, polymer additives are a prerequisite for obtaining crack free films. ${ }^{12}$ Based on previous work by Sekulic et al. and Van Gestel et al., ${ }^{22,23}$ we succeeded in making crack free anatase titania mesoporous coatings on tubes that are suitable as substrates for microporous sol-gel films. The critical layer thickness of these mesoporous titania films before cracking is about 600 $\mathrm{nm}$. This value is much lower than that observed for the boehmite films $(\sim 3 \mu \mathrm{m})$.

\section{Membranes prepared from silica-based sols}

\subsection{PURE SILICA}

Polymeric silica sols are suitable for the preparation of microporous pure silica films on a mesoporous substrate if the interpenetration of the species during the drying phase of a dip-coating process is sufficient. ${ }^{24}$ The preparation of suitable sols from tetraethylorthosilicate (TEOS) by acid catalyzed hydrolysis in ethanol is relatively straightforward. To obtain reproducible sol properties, fresh precursors and well-defined synthesis parameters are required. A suitable formulation is: $\mathrm{TEOS} / \mathrm{EtOH} / \mathrm{H}_{2} \mathrm{O} / \mathrm{HNO}_{3}=1 / 3.8 / 6.4 / 0.085$. ${ }^{18}$ These recipes were first developed at the university of Twente by Uhlhorn, ${ }^{25}$ followed by further developments by De Lange, ${ }^{24}$ and De Vos. ${ }^{26}$ To obtain reproducible sols, it is essential to keep the reaction mixture below $0^{\circ} \mathrm{C}$ during mixing of the reactants. Subsequently, the reaction mixture is quickly heated up to $60^{\circ} \mathrm{C}$, and keep it at this temperature for 3 hours (Scheme 1). Directly after synthesis, the sol is diluted with ethanol, filtered and used in the dip-coating process. Aging of the sol leads to larger pores in the final membrane because of increased branching of the sol species. Using these sols it is possible to obtain microporous silica membranes by a single layer coating on a preconditioned mesoporous $\gamma-\mathrm{Al}_{2} \mathrm{O}_{3}$ substrate. In related work by Brinker et al. ${ }^{27}$ first a larger pore size silica layer was coated on the support, followed by coating of a second microporous layer.

The silica concentration in the sol and the coating speed determine the thickness of the layer formed after dip-coating to a large extent. The critical layer thickness for pure microporous silica layers is about $200 \mathrm{~nm}$. Above this thickness microcracks occur during drying and/or calcining. The average pore size of pure silica thin film determined by gas permeation of several gases was about $0.4 \mathrm{~nm} .{ }^{24}$ SAXS measurements showed that the fractal dimension of the silica species in these sols is about 1.4 to 1.5 , which points to with weakly branched linear species. The radius of gyration was found to be about $2 \mathrm{~nm}$. The hydrothermal stability of pure silica membranes is very limited, resulting in a maximum application temperature in pervaporation applications of $\sim 70^{\circ} \mathrm{C}$ (Figure 6). ${ }^{28}$

Scheme 1. General synthesis scheme for silica-based sols; dashed steps are optional

\subsection{METHYLATED SILICA}

The first approach to increase the hydrothermal stability of the pure silica membrane was by incorporating terminal Si-methyl groups. The reasoning was that by replacing silanol-groups, the surface would become less susceptible to hydrolytic attack. De Vos was the first to develop such a membrane. ${ }^{29}$

In the original recipe ${ }^{29}$ the sol preparation starts with a hydrolysis step similar to that in the pure silica synthesis. After reacting at $60{ }^{\circ} \mathrm{C}$ for 165 min methyltriethoxysilane (MTES, Figure 5) in ethanol is added, leading to final molar ratios of: MTES/TEOS/EtOH/ $\mathrm{H}_{2} \mathrm{O} / \mathrm{HNO}_{3}=$ $1 / 1 / 7.6 / 6.4 / 0.085$. The reaction mixture is cooled down to room temperature $15 \mathrm{~min}$ after the 
addition of MTES, and subsequently diluted with ethanol. The dip-coatings are performed immediately thereafter.

Molecular masses of sol species were investigated by Gel Permeation Chromatography (GPC). The GPC particle size of the methylated silica sol is similar to that of the pure silica sols. The distribution is polydisperse with a maximum molecular mass of $4 \mathrm{~kg} / \mathrm{mol}$. Besides the one-step acid hydrolysis described above, also a two-step acid hydrolysis procedure was developed to prepare methylated silica sols with varying methyl content. ${ }^{30}$ These two step sols have a much smaller GPC particle size distribution with a maximum of $\sim 1 \mathrm{~kg} / \mathrm{mol}$, which has been ascribed to the higher methyl content of the species.

Coatings of these sols on mesoporous $\gamma-\mathrm{Al}_{2} \mathrm{O}_{3}$ and $\mathrm{TiO}_{2}$ could be prepared and the results were very reproducible. The layer thickness can be varied between $50-150 \mathrm{~nm}$ by adjusting the sol concentration and coating speed. The defect density was found to be related to the layer thickness, and increases with decreasing layer thickness (Figure 1d). The calcination of dried films in air at $250^{\circ} \mathrm{C}$ results in membranes with a satisfactory pervaporation performance. The pore size distributions for individual sol and membrane preparations estimated from the uncorrected Kelvin equation using water permporometry ${ }^{31}$ were quite reproducible (Figure 4). The average pore diameter $\mathrm{d} 50$ of about $0.6 \mathrm{~nm}$, is somewhat larger than that of pure silica films. The pervaporation performance of these methylated silica membranes is excellent up to temperatures of $95^{\circ} \mathrm{C}$ (Figure 6). ${ }^{30}$ Above this temperature rapid degradation of the membrane takes place.

Figure 4. Normalized pore size distributions of methylated silica (MeSi) membranes. A, B and C represent individual sol and membrane preparations on mesoporous $\gamma$-alumina substrate tubes; $\mathrm{d} 50 \approx 0.6 \mathrm{~nm}$

\subsection{HYBRID SILICA}

A dramatic increase in hydrothermal stability can be achieved when part of the siloxane bonds (Si-O-Si) are replaced by organic bridges $\left(\mathrm{Si}-\mathrm{CH}_{2}-\mathrm{CH}_{2}-\mathrm{Si}\right)$. As a result a truly organic-inorganic hybrid material is formed. ${ }^{32}$ This hybrid silica material can be obtained through the application of bisfunctional precursors, such as 1,2-bis(triethoxysilyl)ethane (BTESE, Figure 5). The synthesis of sols for such membrane layers was developed by Sah et al. ${ }^{33,34}$ This synthesis consists of a two step acid hydrolysis of BTESE/MTES mixtures. MTES is added to prevent the formation of unreactive cyclic species $^{35}$ and it reduces the speed of gel formation. The two step addition of the acid/water mixture suppresses multiple hydrolysis and therefore promotes the formation of linear and weakly branched sol species. The structure of sol species can be controlled further by the BTESE/MTES ratio, $\mathrm{pH}$, hydrolysis ratio, and reflux time. Based on a screening of acid and water concentrations and the precursor ratio the following composition was selected for membrane preparations: $\mathrm{BTESE} / \mathrm{MTES} / \mathrm{H}_{2} \mathrm{O} / \mathrm{HNO}_{3}=1 / 1 / 2 / 0.05$.

Figure 5. Precursors used for the preparation of silica (TEOS), methylated silica (MTES), and hybrid silica (BTESE) membranes

The average hydrodynamic diameter of these sols ranges from $3-10 \mathrm{~nm}^{36}$ and the fractal dimension of the species as obtained from SAXS is about 1.1. ${ }^{33}$ Based on these data, good particle interpenetration during drying and the formation of micropores is expected. In general, the pore size distributions of the hybrid thin films were broader than those of methylated silica membranes. The average pore diameter estimated from permporometry is also slightly larger ( $\mathrm{d} 50=0.6-0.9$ $\mathrm{nm})$. A striking feature of the hybrid films is the unusually large critical layer thickness of about 1 $\mu \mathrm{m}$. Presumably, this is a consequence of the presence of the bridging alkyl groups which decrease the elasticity modulus of the film, i.e. enhancing the possibilities for viscous relaxation.

Above, we have shown that the maximum application temperature of pure and methylated silica in the pervaporation of $n$-butanol/water is limited to a maximum value of $95^{\circ} \mathrm{C} .{ }^{30}$ The hybrid silica membranes show remarkably stable performance at temperatures as high as $150{ }^{\circ} \mathrm{C}$. These 
membranes have excellent water fluxes and selectivity and maintain this performance up to at least 600 days of total running time (Figure 6). ${ }^{33}$ We believe that several factors play a critical role in the differences in stability between silica, methylated silica, and hybrid silica membranes. The presence of organic groups in the structure leads to a more hydrophobic character and the silicon atoms are partly shielded from attack by water. In addition, the network in this hybrid silica is partly formed by silicon-carbon bonds that do not hydrolyze. Furthermore, the bridging momomers are connected via six siloxane groups compared to four or three in TEOS and MTES respectively. This characteristic of bisfunctional precursors lowers the probability of full hydrolysis and subsequent removal of monomers from the membrane film.

Figure 6. Long-term performance of silica-based membranes in pervaporation

In addition to the above, we believe that mechanical factors are of importance. Pure silica sols obtained by acid hydrolysis contain a relatively large content of 3 and 4 membered strained siloxane rings. ${ }^{37}$ The content of these strained rings may even increase during the dip-coating process and the subsequent drying and calcining. It has been suggested that especially these strained bonds are susceptible to hydrolysis followed by a restructuring to a more favorable relaxed structure. ${ }^{38}$ This transforms microporous silica in dense silica with some remaining mesoporosity.

The incorporation of (non-binding) methyl groups probably retards the restructuring of the silica network, which explains the increased stability of methylated silica. This effect is exponentially larger in the presence of bridging $-\mathrm{Si}-\mathrm{CH}_{2}-\mathrm{CH}_{2}-\mathrm{Si}$ groups. The formation of threemembered rings is much more unlikely using the bridging precursors. Tensile film stresses increase the sensitivity for water attack similar to the presence of strained three membered rings. ${ }^{39}$ We think the possibilities for stress relaxation in the hybrid membrane films are larger hence decreasing the reactivity for water. In addition, recent studies on the use of such materials as insulators for microelectronic devices have shown that crack propagation is retarded by the incorporation of organic bridging groups in the silica network. ${ }^{40}$

\section{Membranes prepared from metal oxide sols}

As an alternative to silica-based materials we have investigated metal oxides, such as titania and zirconia. These metal oxides are known for their stability in aqueous environment in a wide $\mathrm{pH}$ range. ${ }^{23,41}$ A number of different routes have been employed for the sol-gel synthesis of metal oxide particles. Most of these aim at the limitation of reaction kinetics involved in the sol-synthesis based on alkoxide precursors. Two main approaches can be distinguished. One approach uses ligands to stabilize the precursor (Scheme 2), ${ }^{42-46}$ the other is based on stabilization of nanoparticles before they aggregate (Scheme 3$).{ }^{47}$ For the first approach, ligands such as amino-alcohols or $\beta$-diketones are used, of which acetylaceton (acac) is the best-known example. Aggregation of nanoparticles can be prevented by the introduction of an acid dispersant or by using a sub-stoichiometric amount of water. We have used both approaches for the preparation of titania and zirconia thin films.

Scheme 2. General route for ligand-based metal oxide sol preparation

\subsection{TITANIA}

Titania sols were prepared by premixing acac and titanium isopropoxide in isopropanol (IPA) in a molar ratio of $1: 1$ (sol Ti-1). To this mixture a solution of water in IPA was added slowly, leading to a final molar ratio $\mathrm{H}_{2} \mathrm{O} / \mathrm{Ti}$ of $2: 1$. Using this approach, sol particles with an average hydrodynamic diameter of $2 \mathrm{~nm}$ were obtained. Coatings on $\gamma$-alumina support tubes resulted in very thin layers that appeared to be defect-free by microscopy techniques. However, pore size analysis by permporometry indicated the presence of smaller mesopores. This is an indication that no complete coverage of the mesoporous support was achieved. We presume that the small particle 
size obtained by this route leads to sol infiltration into the support rather than the formation of a porous layer on top of the support.

In a second approach the aim was to prevent aggregation of particles during sol synthesis. This time a mixture of water, concentrated $\mathrm{HNO}_{3}$, and IPA was added dropwise to titanium isopropoxide in IPA ${ }^{47}$ We used water to titanium ratios of $1.4: 1$ (sol Ti-2) and $2: 1$ (sol Ti-3). After addition of the water mixture, the sols were heated to reflux for 10 min and aged for 1 day before coating. The average particle size of sol Ti-2, prepared with lower amount of water, was smaller than that of sol Ti-3, prepared with a stoichiometric water content. In addition, the size distribution is somewhat broader for sol $\mathrm{Ti}-2$. Sol Ti-C has a narrow size distribution with an average hydrodynamic diameter of $10 \mathrm{~nm}$ (Figure 7). The particle size distribution of sols Ti-2 and Ti-3 did not change over time for at least one week.

Scheme 3. General preparation of metal oxide sols using acid (used for zirconia) or a substoichiometric amount of water (used for titania)

Figure 7. Dynamic light scattering results showing the hydrodynamic diameter of titania (sol Ti-3) and zirconia (sol Zr-2) sols

\subsection{ZIRCONIA}

A ligand-based zirconia sol was prepared using acac as modifying ligand (Sol Zr-1). Similar to the titania sol, a solution of zirconium $n$-propoxide in $n$-propanol was mixed with a solution of acac in $n$-propanol in a ratio of $1: 1$. To this modified precursor a solution of water in $n$-propanol was added drop-wise in a molar ratio $\mathrm{H}_{2} \mathrm{O} / \mathrm{Zr}$ of $2: 1$. The mixture was stirred for $1 \mathrm{~h}$ after which the sol was ready for coating. Similar to sol Ti-1 this ligand-modified sol resulted in defect-free layers that infiltrate into the mesoporous support.

Different from our work on titania, a second type of zirconia sol was based on a approach inspired by microemulsions. ${ }^{48}$ First a mixture water, hexanol, and cyclohexane was stirred vigorously. This mixture was added drop-wise to a solution of zirconium $n$-propoxide in cyclohexane in a molar ratio $\mathrm{H}_{2} \mathrm{O} / \mathrm{Zr}$ of $3: 1$. Subsequently, the resulting sol was stirred for $15 \mathrm{~min}$ and acetic acid in cyclohexane was added in one portion. After this the sol was ready for further use (sol Zr-2).

The dynamic light scattering experiments for zirconia sols based on the second approach indicate that the hydrodynamic diameters are in the nanosize range and that the size distributions are quite narrow. The average hydrodynamic diameters of these sols are around 5-7 nm (Figure 7). Interestingly, when the same sol preparation was repeated and the sols were aged for different periods of time, the size distributions found with DLS are very similar. Clearly, the sol preparation using a microemulsion is highly reproducible and the sols are highly stable against particle growth.

Based on these measurements the membranes based on titania sols Ti-3 and zirconia sol $\mathrm{Zr}-2$ were selected for further investigation. Pervaporation measurements were carried out at $95{ }^{\circ} \mathrm{C}$ using a mixture of $n$-butanol and water $(95 / 5 \mathrm{w} \%)$. The zirconia membrane has an initial water flux of around $5 \mathrm{~kg} / \mathrm{m}^{2} . \mathrm{h}$, which decreases during the first 20 days of operation. After 20 days, the membrane performance is stable up to at least 120 days. The measurement was terminated after 123 days. The water content of the permeate stream initially is quite low, but after about 20 days an acceptable $90 \%$ water is reached. This increases to the required $95 \%$ after 40 days.

The titania membrane also has an initial water flux of over $5 \mathrm{~kg} / \mathrm{m}^{2}$.h. Also in this case, the flux decreases rapidly during the first 20 days of operation. In addition, the water content in the permeate stream starts at a disappointing $75 \%$, rises to $95 \%$, after which the water content drops dramatically. This is a clear indication for breakdown of the membrane after about 15 days.

The titania membrane based on sol Ti-2 was selected for nanofiltration experiments in supercritical $\mathrm{CO}_{2}$. Microporous membranes, such as silica membranes and the titania membrane 
described here are very effective in retaining a fluorinated phosphine complex, a modified version of Wilkinsons complex. ${ }^{49}$

Based on our data it seems that the zirconia membranes, and more heavily the titania membranes, suffer from densification and crystallization effects. It has to be noted that the actual process conditions for pervaporation resemble many of the hydrothermal treatments done to prepare crystalline nanoparticles. Therefore, the conditions of the separation process could easily provide the energy to transform the material to its thermodynamically favorable state.

\section{Outlook}

In this chapter we have presented a brief overview of the use of different sol-gel approaches for the formation of microporous membranes. The examples indicate that such membranes are highly suitable for molecular separations. Still, the issue of long-term stability in media that contain water, or in addition are highly acidic or basic needs to be addressed. The sol tailoring we and others have done shows that particle morphology and size can be directed by choosing the right precursors, reaction conditions, and stabilizing agents.

The remarkable stability of the first generation of microporous hybrid membranes indicates that much can be gained by including organic groups in the network structure. We feel that the field of membrane science would benefit from additional studies into the nature of this stabilizing effect. The potential of hybrid materials for membrane applications poses a great challenge for solscientists, because of the vast amount of possible variations.

The limited life-time of membranes based on titania and zirconia sols suggest that the use of (partly) amorphous mono-metal oxide sol species does not lead to membranes that have long-term stability. In our view, the development of sols for membrane preparation should either focus on stabilization of amorphous structures by, e.g. dopants, or on the use of crystalline nanoparticle sols. As an additional advantage, the surface of crystalline nanoparticle can be tailored to the application, as was nicely demonstrated by the group of Niederberger. ${ }^{50,51}$ Recent work on mixed metal precursors by Spijksma et al. opens the way for amorphous mixed oxide membranes. ${ }^{52}$ The use of these mixed metal oxides for membrane applications could improve stability by preventing the phase changes commonly observed for titania and zirconia.

Over the years, the field of sol-gel science has had a large influence on the development of membranes that have to survive under industrial, often corrosive conditions. Based on the described recent developments in the field of sol-gel membranes, we conclude that membrane science still is a challenging topic for sol-gel scientists.

\section{References}

1. M. Asaeda, Sol-gel derived ceramic membranes for separation of molecular mixtures, Porous. Ceram. Mater., Conf. Proc. (2005).

2. J. F. Vente, H. M. van Veen, and P. P. A. C. Pex, Microporous sol-gel membranes for molecular separations, Ann. Chim. Sci. Mat. 32 (2), 231-244 (2007).

3. B. C. Bonekamp, A. van Horssen, L. A. Correia, J. F. Vente, and W. G. Haije, Macroporous support coatings for molecular separation membranes having a minimum defect density, J. Membr. Sci. 278 (1-2), 349-356 (2006).

4. P. P. A. C. Pex and Y. C. van Delft, in: Carbon dioxide capture for storage in deep geological formations, 1 ed., edited by D. C. Thomas, and S. M. Benson, (Elsevier Science, Amsterdam, 2005), pp. 307-319.

5. C. J. Brinker, Porous inorganic materials, Curr. Opin. Solid State Mater. Sci. 1, 798-805 (1996).

6. H. M. van Veen, Y. C. van Delft, C. W. R. Engelen, and P. P. A. C. Pex, Dewatering of organics by pervaporation with silica membranes, Separ. Purif. Techn. 22-23, 361-366 (2001).

7. C. J. Brinker, R. Sehgal, S. L. Hietala, R. Deshpande, D. M. Smith, D. A. Loy, and C. S. Ashley, Sol-gel strategies for controlled porosity inorganic materials, J. Membr. Sci. 94, 85-102 (1994).

8. A. W. Burton and S. I. Zones, in: Introduction to zeolite science and practice, edited by J. Cejka, H. van Bekkum, A. Corma, and F. Schüth, (Elsevier, Amsterdam, 2007), pp. 137-179. 
9. C. J. Brinker, and G. W. Scherer, Sol-gel science - the physics and chemistry of sol-gel processing (Academic Press, New York, 1990).

10. C. J. Brinker, N. K. Raman, M. N. Logan, R. Sehgal, R. A. Assink, D.-W. Hua, and T. L. Ward, Structureproperty relations in thin films and membranes, J. Sol-gel Sci. Technol. 4, 117-133 (1995).

11. A. C. Pierre, Introduction to sol-gel processing (Kluwer Academic Publ., 1998).

12. A. J. Burggraaf, in: Fundamentals of inorganic membrane science and technology, edited by A. J. Burggraaf, and L. Cot, (Elsevier Science, Amsterdam, 1996).

13. A. Rawle, The importance of particle sizing to the coatings industry Part 1: Particle size measurement, Adv. Col. Sci. Technol. 5 (1), 1-12 (2002).

14. C. J. Brinker, Review of sol-gel thin film formation, J. Non-Cryst. Solids 147/148, 424-436 (1992).

15. A. J. Hurd and L. Steinberg, The physics of evaporation-induced assembly of sol-gel materials, Granular Matter 3(1-2), 19-21 (2001).

16. C. Nguyen, K. R. Carter, C. J. Hawker, R. L. Jaffe, R. D. Miller, J. F. Remenar, H.-W. Rhee, P. M. Rice, M. F. Toney, M. Trollsås, and D. Y. Yoon, Low-dielectric nanoporous organosilicate films prepared via inorganic/organic polymer hybrid templates, Chem. Mater. 11, 3080-3085 (1999).

17. G. Reiter, Dewetting of thin polymer films, Phys.Rev.Lett. 68, 75-82 (1992).

18. R. M. de Vos and H. Verweij, High-selectivity, high-flux silica membranes for gas separation, Science 279 , 1710-1711 (1998)

19. B. C. Bonekamp, in: Fundamentals of Inorganic Membrane Science and Technology, Volume 4, edited by A. J. Burggraaf and L. Cot, (Elsevier, Amsterdam, 1996).

20. B. E. Yoldas, Alumina gels that form porous transparant $\mathrm{Al}_{2} \mathrm{O}_{3}$, J. Mater. Sci. 10, 1856-1860 (1975).

21. A. F. M. Leenaars, K. Keizer, and A. J. Burggraaf, The preparation and characterization of alumina membranes with ultra-fine pores, Part 1, Microstructural investigations om non supported membranes, $\mathrm{J}$. Mater. Sci. 19, 1077 (1984).

22. J. Sekulić, A. Magraso, J. E. ten Elshof, and D. H. A. Blank, Influence of $\mathrm{ZrO}_{2}$ addition on microstructure and liquid permeability of mesoporous $\mathrm{TiO}_{2}$ membranes, Micropor. Mesopor. Mater. 72, 49-57 (2004).

23. T. van Gestel, C. Vandecasteele, A. Buekenhoudt, C. Dotremont, J. Luyten, R. Leysen, B. van de Bruggen, and G. Maes, Alumina and titania multilayer membranes for nanofiltration: preparation, characterization and chemical stability, J. Membr. Sci. 207, 73-89 (2002).

24. R. S. A. de Lange, K. Keizer, and A. J. Burggraaf, Aging and stability of microporous sol-gel-modified ceramic membranes, Ind. Eng. Chem. Res. 34, 3838-3847 (1995).

25. R. J. Uhlhorn, Ceramic membranes for gas separation. Ph.D, thesis, University of Twente (1990).

26. R. M. de Vos and H. Verweij, Improved performance of silica membranes for gas separation. J. Membr. Sci.143, 37-51 (1998).

27. C. J. Brinker, C. Y. Tsai, and Y. Lu, Inorganic dual-layer microporous supported membranes. US6536604 (2003)

28. T. A. Peters, J. Fontalvo, M. A. G. Vorstman, N. E. Benes, R. A. van Dam, Z. A. E. P. Vroon, E. L. J. van Soest-Vercammen, and J. T. F. Keurentjes, Hollow fiber microporous silica membranes for gas separation and pervaporation. Synthesis, performance and stability, J. Membr. Sci. 248, 73-80 (2004).

29. R. M. de Vos, W. F. Maier, and H. Verweij, Hydrophobic silica membranes for gas separation. J. Membr. Sci. 158 (1-2), 277-288 (1999).

30. J. Campaniello, C. W. R. Engelen, W. G. Haije, P. P. A. C. Pex, J. F. Vente, Long-term pervaporation performance of microporous methylated silica membranes, Chem. Commun. 834-835 (2004).

31. T. Tsuru, T. Hino, T. Yoshioka, and M. Asaeda, Permporometry characterisation of microporous ceramic membranes, J. Membr. Sci., 186 (2), 257-265 (2001).

32. K. J. Shea and D. A. Loy, Bridged polysilsesquioxanes, molecular-engineered hybrid organic-inorganic materials, Chem. Mater., 13, 3306-3319 (2001).

33. H. L. Castricum, A. Sah, R. Kreiter, D. H. A. Blank, J. F. Vente, and J. E. ten Elshof, Hybrid organosilica membranes: molecular separation under hydrothermal conditions. submitted (2007).

34. A. Sah, Chemically modified ceramic membranes - study of structural and transport properties, Ph.D. thesis, University of Twente (2006).

35. D. A. Loy, J. P. Carpenter, T. M. Alam, R. Shaltout, P. K. Dorhout, J. Greaves, J. H. Small, and K. J. Shea, Cyclization Phenomena in the Sol-Gel Polymerization of $\alpha, \omega$-bis(triethoxysilyl)alkanes and incorporation of the cyclic structures into network silsesquioxane polymers, J. Am. Chem. Soc., 121, 5413-5425 (1999).

36. H. L. Castricum, R. Kreiter, J. F. Vente, and J. E. ten Elshof, to be published.

37. C. J. Brinker, W. L. Warren, and S. Wallace, in: Structure and Imperfections in Amorphous and Crystalline Silicon Dioxide, edited by R. A. B. Devine, J.-P. Duraud, and E. Dooryhée, (J. Wiley \& Sons, Chichester, 2000), pp. 475-493.

38. R. M. van Ginhoven, H. Jónsson, B. Park, and L. R. Corrales, Cleavage and recovery of molecular water in silica, J. Phys. Chem. B, 109(21), $10936-10945$ (2005).

39. T. A. Michalske and B. C. A. Bunker, Chemical kinetics model for glass fracture, J. Am. Ceram. Soc., 76, 2613-2618 (1993).

40. G. Dubois, W. Volksen, T. Magbitang, R. D. Miller, D. M. Gage, and R. H. Dauskardt, Molecular network reinforcement of sol-gel glasses, Adv. Mater., doi: 10.1002/adma.200701193 (2007)

41. G. I. Spijksma, Modification of zirconium and hafnium alkoxides - the effect of molecular structure on derived materials, Ph.D. thesis, University of Twente (2006). 
42. G. A. Seisenbaeva, S. Gohil, and V. G. Kessler, Influence of heteroligands on the composition, structure and properties of homo- an heteremetallic ziconium alkoxides. Decisive role of thermodynamic factors in their self-assembly, J. Mater. Chem., 21, 3177-3190 (2004).

43. G. A. Seisenbaeva, S. Gohil, and V. G. Kessler, Molecular design approach to a highly soluble and volatile bimetallic alkoxide of late transition metal and zirconium. Synthesis, X-ray single crystal and mass-spectral study of $\mathrm{NiZr}_{2}$ (acac)(OiPr), Inorg. Chem. Commun., 10, 94-96 (2007).

44. G. I. Spijksma, H. J. M. Bouwmeester, D. H. A. Blank, and V. G. Kessler, Stabilization and destabilization of zirconium propoxide precursor by acetylacetone, Chem. Commun., 1874-1875 (2004).

45. L. Armelao, C. Eisenmenger-Sittner, M. Groenewolt, S. Gross, C. Sada, U. Schubert, E. Tondello, and A. Zattin, Zirconium and hafnium oxoclusters as molecular building blocks for highly dispersed $\mathrm{ZrO}_{2}$ or $\mathrm{HfO}_{2}$ nanoparticles in silica thin films, J. Mater. Chem., 15, 1838-1848 (2005).

46. U. Schubert, Organofunctional metal oxide clusters as building blocks for inorganic-organic hybrid materials, J. Sol-Gel Sci. Technol., 31, 19-24 (2004).

47. J. Sekulić, J. E. ten Elshof, and D. H. A. Blank, A microporous titania membrane for nanofiltration and pervaporation, Adv. Mater., 16 (17), 1546-1550 (2004).

48. S. E. Friberg and J. Sjöblom, in: Industrial applications of microemulsions, edited by C. Solans and H. Kunieda, (Marcel Dekker, New York, 1997); pp. 267-277.

49. E. L. V. Goetheer, A. W. Verkerk, L. J. P. van den Broeke, E. de Wolf, B.-J. Deelman, G. van Koten, and J. T. F. Keurentjes, Membrane reactor for homogeneous catalysis in supercritical carbon dioxide, J. Catal., 219, 126-133 (2003).

50. G. Garnweitner and M. Niederberger, Nonaqueous and surfactant-free synthesis routes to metal oxide nanoparticles, J. Am. Ceram. Soc., 89 (6), 1801-1808 (2006).

51. M. Niederberger, G. Garnweiter, F. Krumeich, R. Nesper, H. Cölfen, and M. Antonietti, Tailoring the surface and solubility properties of nanocrystalline titania by a nonaqueous in situ functionalization process, Chem. Mater., 16, 1202-1208 (2005).

52. G. I. Spijksma, C. Huiskes, N. E. Benes, H. Kruidhof, D. H. A. Blank, V. G. Kessler, H. J. M. Bouwmeester, Microporous zirconia-titania composite membranes derived from diethanolamine-modified precursors, $A d v$. Mater., 18, 2165-2168 (2006). 

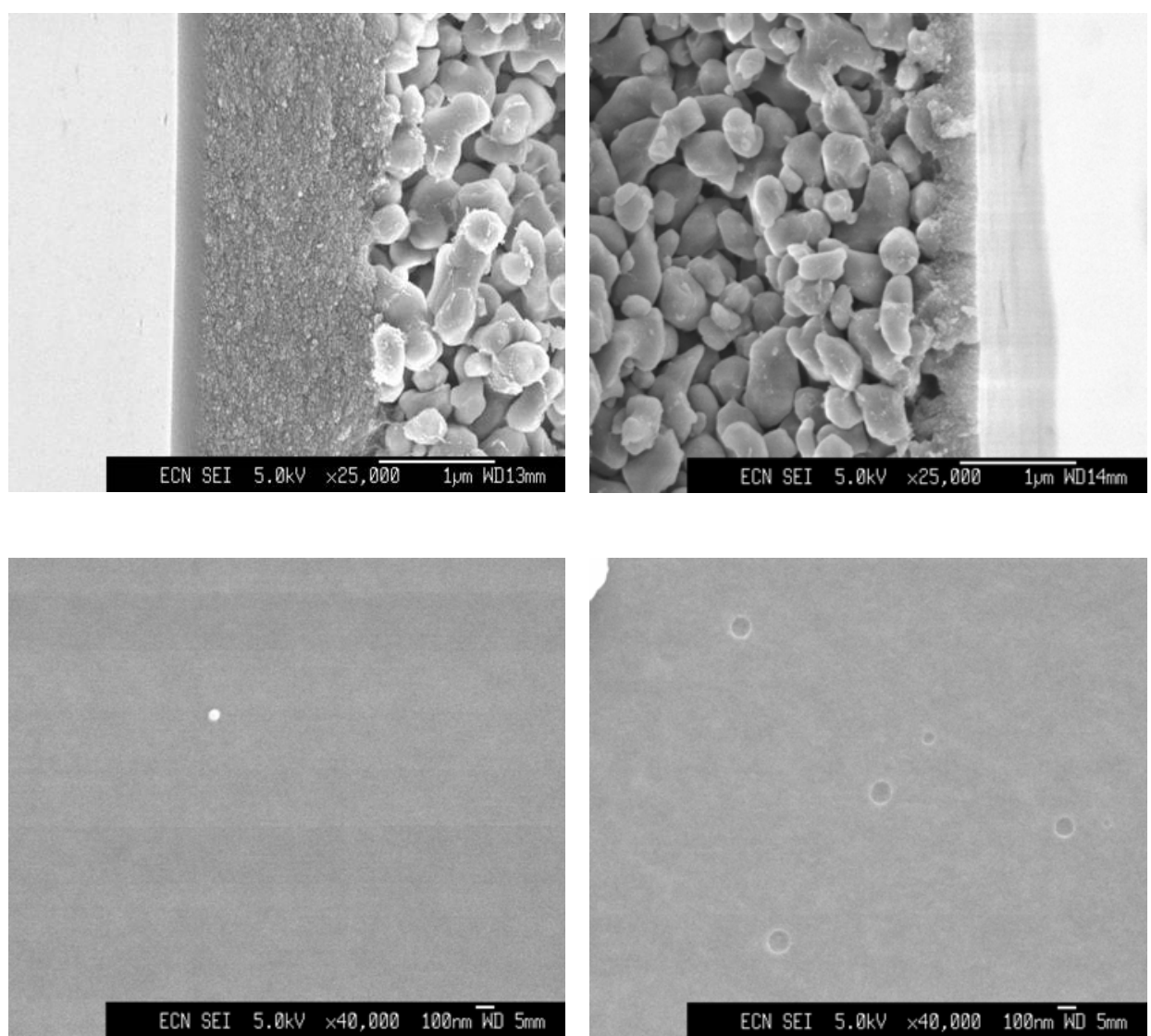

Figure 1. SEM pictures of a. fracture surface of a microporous silica sol-gel film on a mesoporous $\gamma$-alumina substrate; $b$. mesoporous titania sol-gel film on a macroporous $\alpha$-alumina substrate; c. surface of a microporous methylated silica thin film; d. methylated silica thin film $(\sim 50 \mathrm{~nm})$
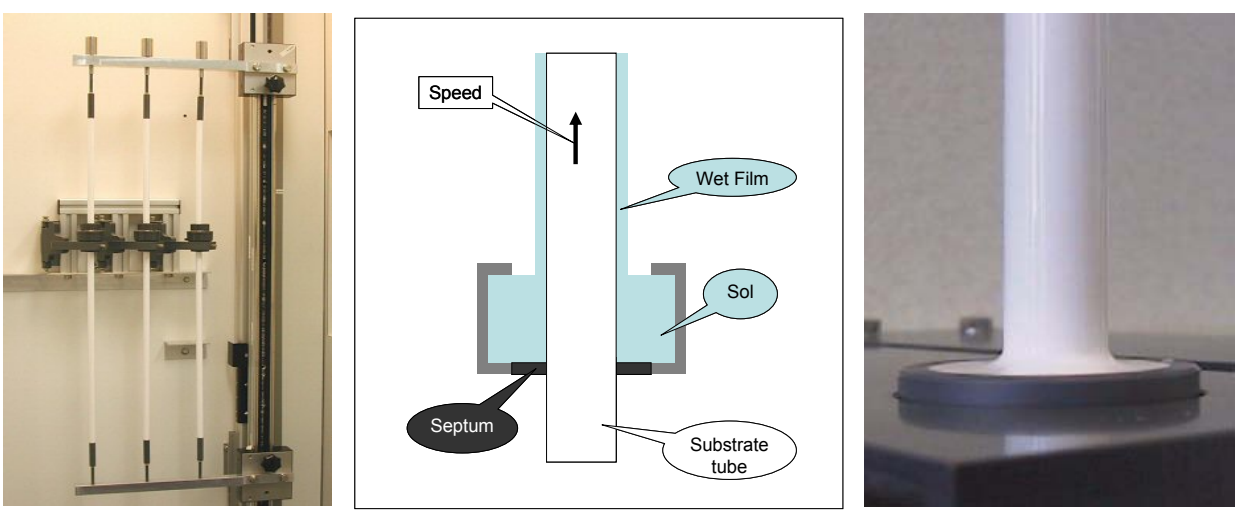

Figure 2. Dip-coating of membrane tubes 

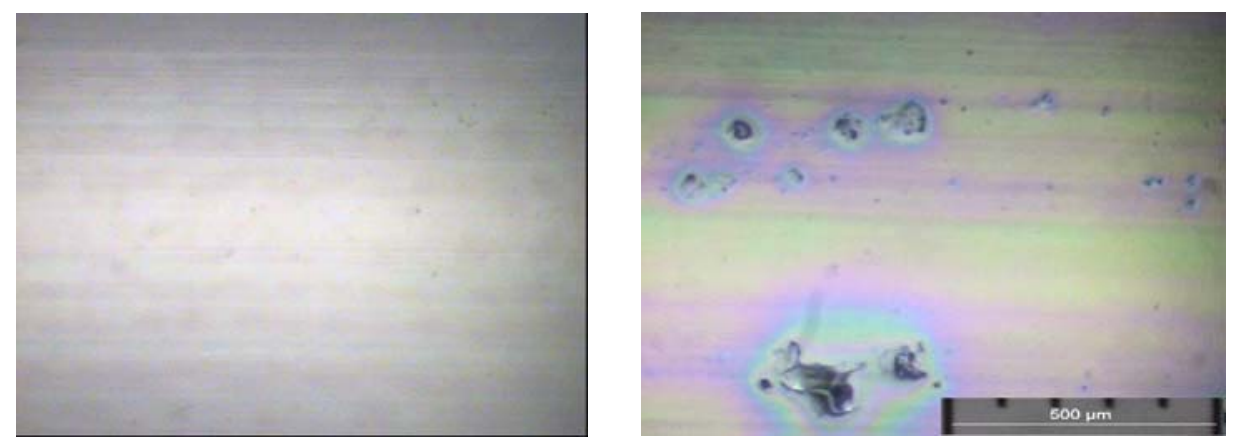

Figure 3. Optical micrographs of the surface of a microporous zirconia thin film having a high defect density (left) and a defect poor microporous methylated silica thin film (right)

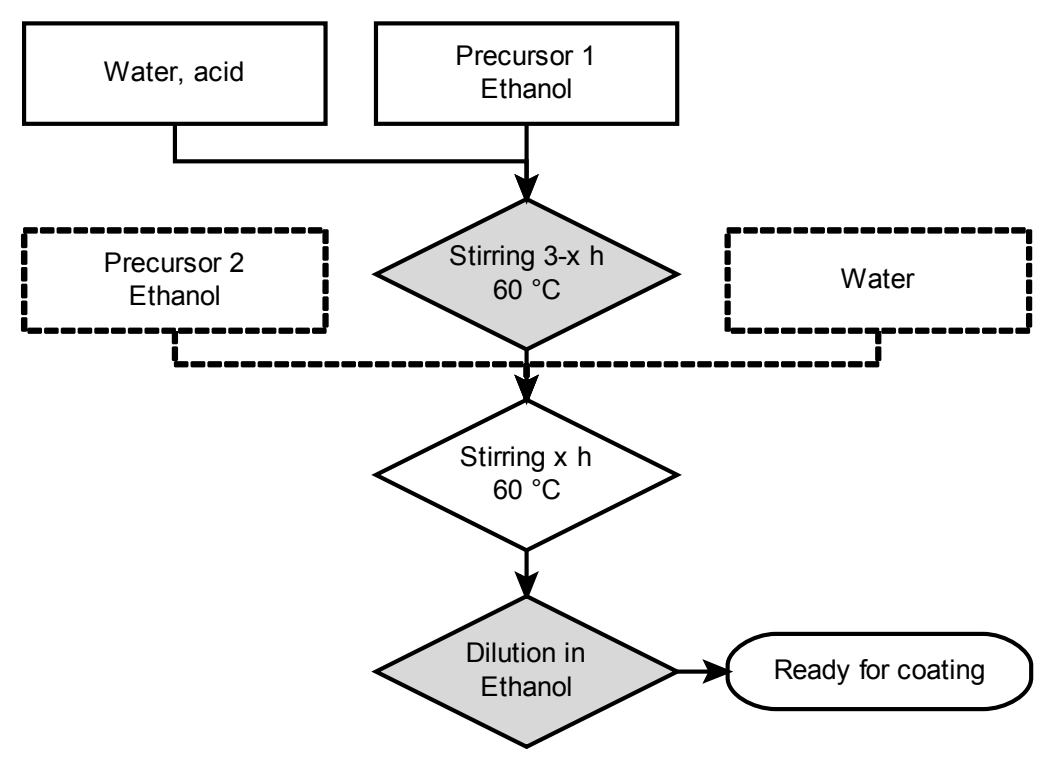

Scheme 1. General synthesis scheme for silica-based sols; dashed steps are optional 


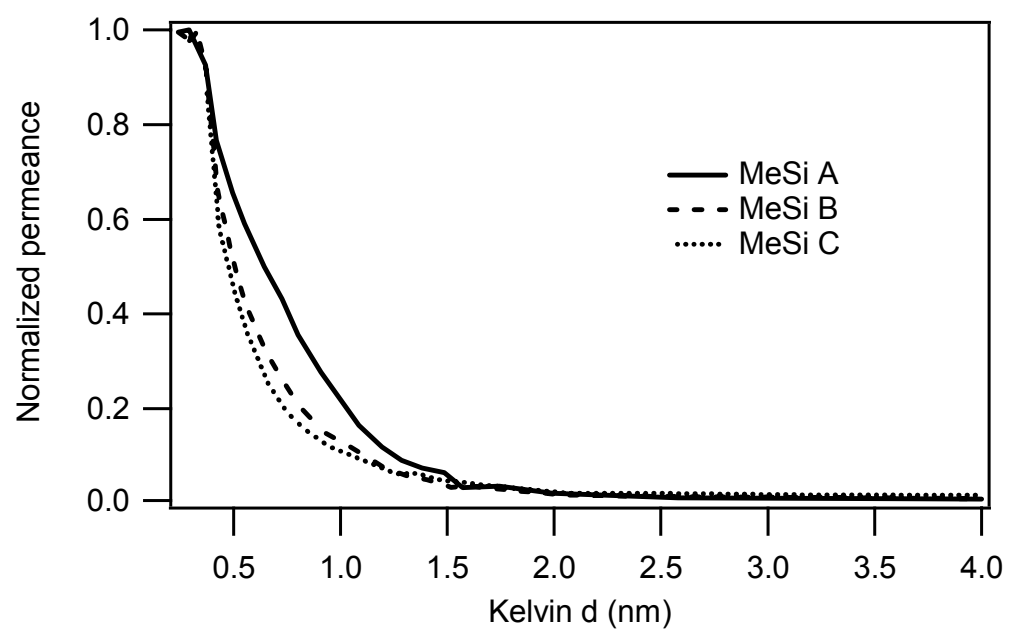

Figure 4. Normalized pore size distributions of methylated silica (MeSi) membranes. A, B and C represent individual sol and membrane preparations on mesoporous $\gamma$-alumina substrate tubes; $\mathrm{d} 50 \approx 0.6 \mathrm{~nm}$<smiles>CCO[Sb](OCC)(OCC)OCC</smiles>

TEOS<smiles>CCO[Si](C)(OCC)OCC</smiles>

MTES<smiles>CCO[Si](CC[Si](OCC)(OCC)OCC)(OCC)OCC</smiles>

BTESE

Figure 5. Precursors used for the preparation of silica (TEOS), methylated silica (MTES), and hybrid silica (BTESE) membranes

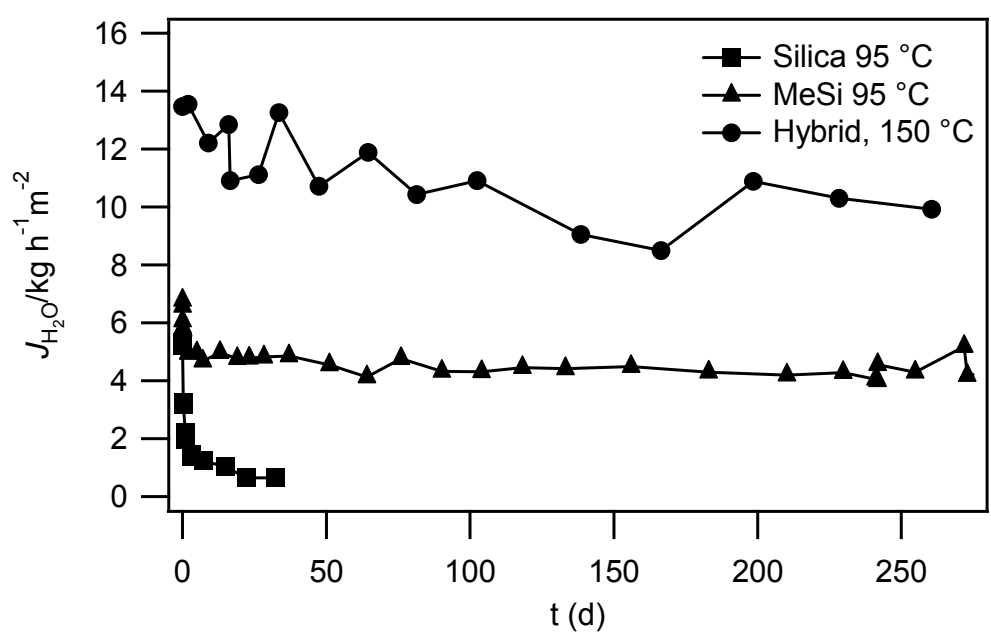

Figure 6. Long-term performance of silica-based membranes in pervaporation 


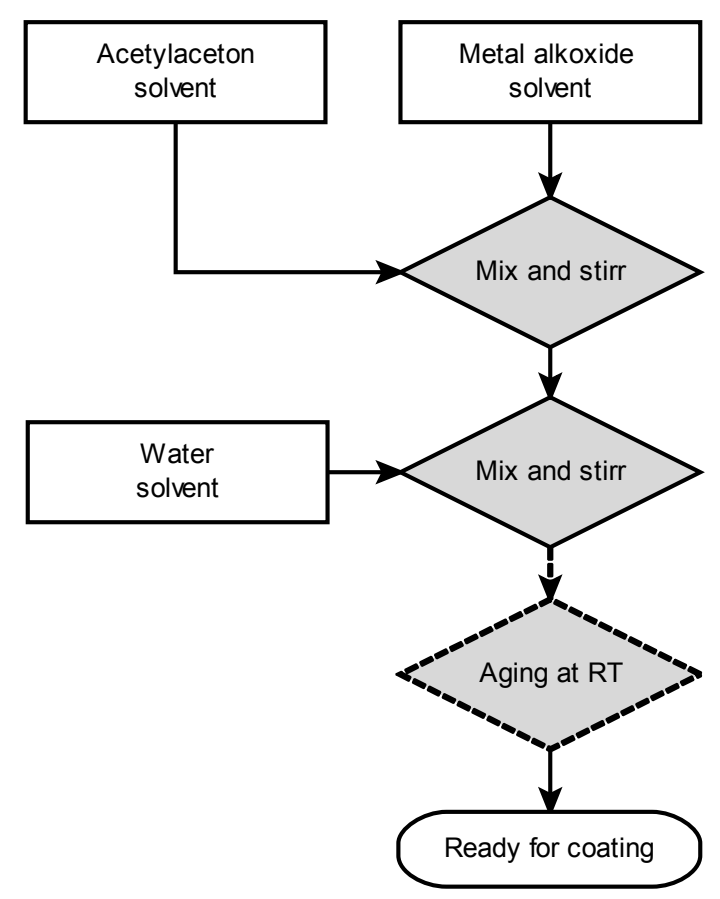

Scheme 2. General route for ligand-based metal oxide sol preparation 


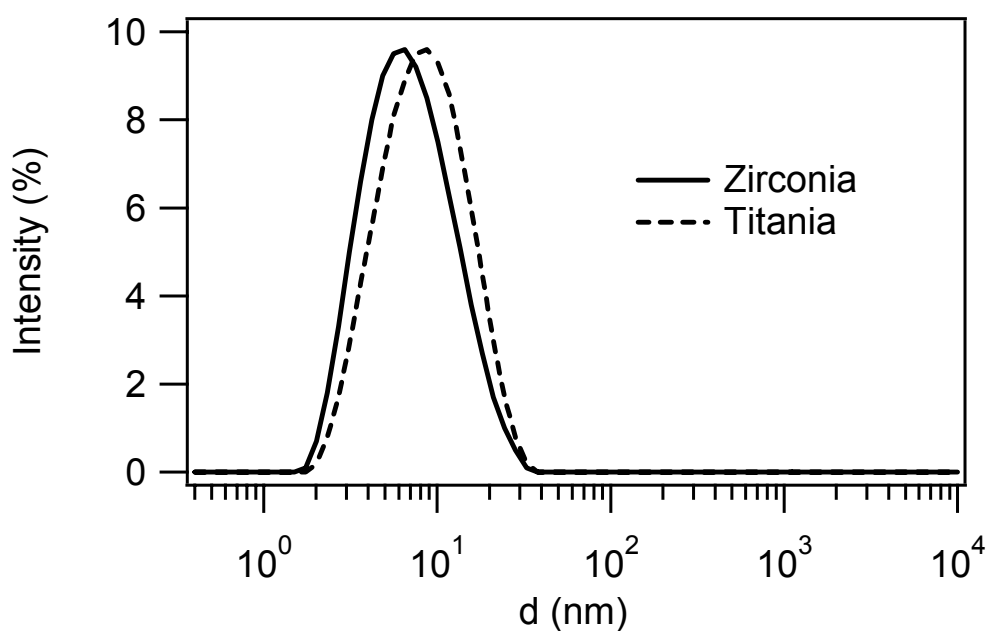

Figure 7. Dynamic light scattering results showing the hydrodynamic diameter of titania (sol Ti-3) and zirconia (sol Zr-2) sols

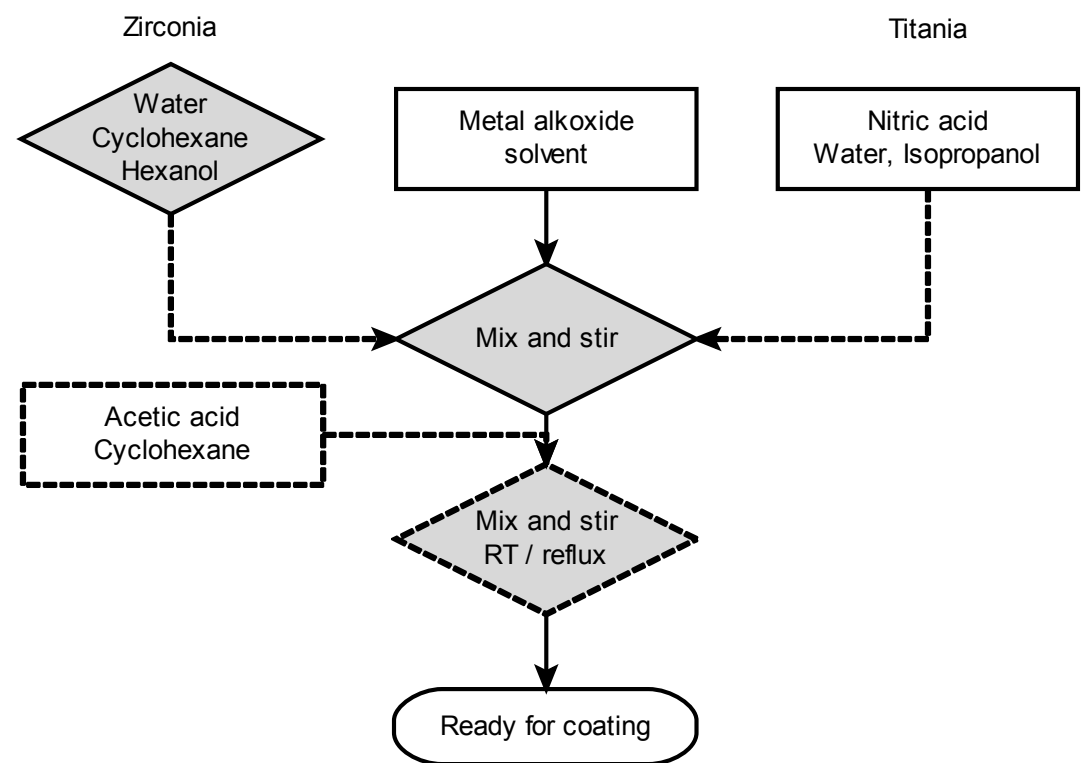

Scheme 3. General preparation of metal oxide sols using acid (used for zirconia) or a substoichiometric amount of water (used for titania) 